\title{
BUSINESS
}

\section{Swiss on a roll}

\section{Smart investors who know the drugs business well are helping to make Zurich's stock market a popular place for biotechnology firms to raise money. Andrea Chipman reports.}

$\Lambda$ $\mathrm{t}$ a time when biotechnology companies worldwide are finding it tough to raise money, the Swiss Exchange (SWX) in Zurich is proving to be an alluring financial home.

"It's an excellent stock market that took the initiative ten years ago to build up a biotech medical segment that makes it attractive," says Ulrich Steiner, an analyst at Swiss bank Clariden Leu in Zurich, adding that smaller biotech companies find it easier to be noticed by investors and raise their profiles in Switzerland. "If you go into the London stock market, there are two to three listings every day and a lot of companies that investors could choose to invest in. In Switzerland, there's maybe one new listing every four to six weeks."

Life-sciences companies make up a large proportion of the market, accounting for one-third of total market capitalization on the SWX, or around $€ 245$ billion (US $\$ 335$ billion), which includes some major international pharmaceutical companies. That's the largest concentration of its kind in Europe, according to the Swiss Biotech Report 2007, a survey published in April by Ernst \& Young, the Swiss government and other parties.

When it comes to the drugs business, Switzerland has lots of advantages. Aside from more than 200 established biotech companies, and some of the world's largest pharmaceutical firms, such as Novartis and Roche, it has an extensive biotechnology infrastructure. Wellfunded universities, federal and cantonal government support for fledgling companies and a host of organizations and initiatives that provide coaching, promotion, advice and patentapplication help for start-ups have nutured the sector. Identifiable biotech clusters have developed in four regions of the country.

And many of the factors that have made Switzerland a friendly place for biotech start-ups - a favourable tax environment and a multilingual population and workforce - have also attracted investors and analysts with a highly specialized biotechnology knowledge, market-watchers say. Although most of the life-sciences companies on the SWX are home-grown, foreign ones are increasingly taking notice. In 2006, two out of three initial public

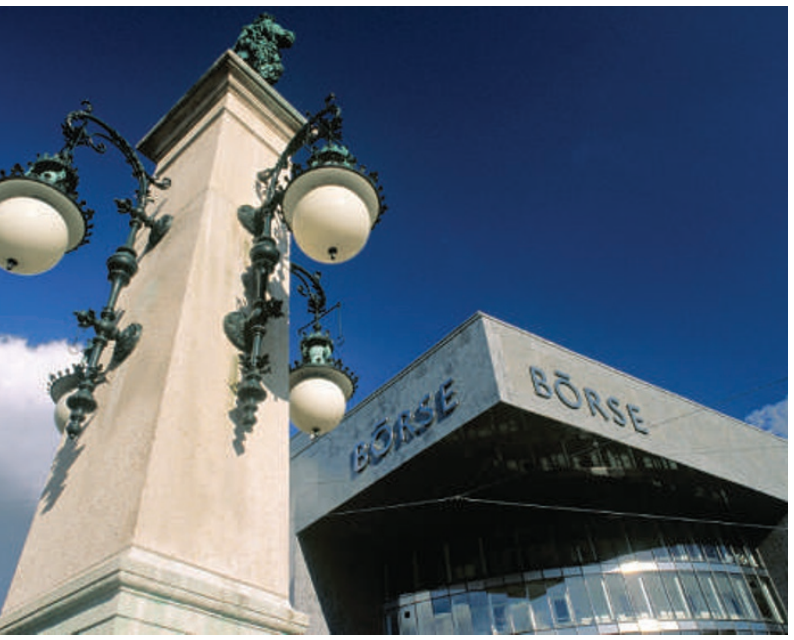

One-third of the money in Zurich's bourse relates to life science.

$€ 75$ million by floating on the SWX. According to Stefan Weber, the company's chief financial officer, it scoured the world's stock markets beforehand: it excluded Nasdaq after deciding that it would need to base a major part of its operations in the United States to gain the attention of US investors. Weber says that didn't make sense, adding that the Sarbanes-Oxley financial reporting regulations and the difficulties of getting analysts to cover any company worth less than $\$ 500$ million also kept the company away from Nasdaq.

Newron also discounted most of the major European stock markets including its home market of Milan - because of the generally unimpressive performance of life-sciences

offerings (IPOs) in biotech companies were from over the border, including Italian companies BioXell and Newron - spin-offs of Roche and Pharmacia \& Upjohn, respectively. The total volume of companies debuting on the market remains modest compared with those of London and New York, however.

Investors are encouraged by the recent performance of Zurich's sector-specific indices, such as SXI Life Sciences and SXI Bio+Medtech, which have tended to outperform similar measures in Frankfurt and London (see graph).

And according to Jürg Zürcher, an industry analyst at Ernst \& Young in Basel, the SWX raised more money from biotech IPOs in 2006 than any other stock exchange in Europe.

Last December, for example, Newron of Milan, Italy - a company specializing in treatments for disorders of the central nervous system and pain management — raised

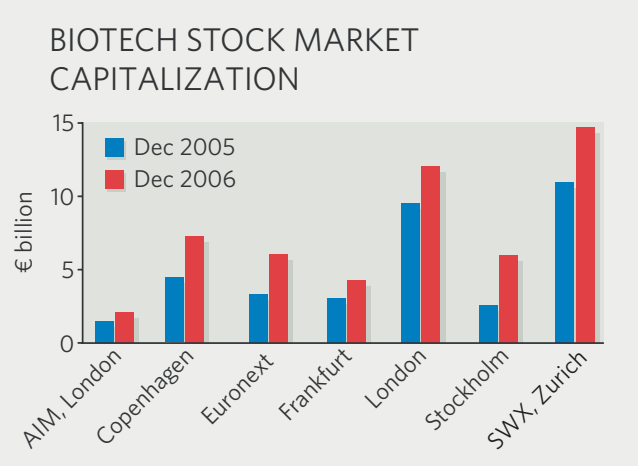
companies there both before and after share offerings. In Milan, the shortage of specialized indices, investors, investment banks and analyst coverage counted against it. Turning to the London markets, Newron weighed the higher market capitalization and global sales of the London Stock Exchange against the lack of specialized sector coverage. When it came to London's Alternative Investment Market (AIM), Newron was sceptical about its abilities to compete for coverage and market attention with lots of other small companies that Weber characterizes as "low-quality".

"We thought we had a premium business case," he says. "We wanted to have the best environment possible." That meant Switzerland, where Newron was able to do a fully international flotation, with $70 \%$ of investors coming from outside the country.

Switzerland's markets are dominated by wellknown private banks and a large number of wealthy individual retail investors. That fits better with the biotechnology industry than the fast-paced trading cultures in London and New York do, analysts say.

"The specific criteria of life-science stocks are different from, say, those of a car manufacturer," explains Hanns-Peter Wiese, a partner at Munich-based Global Life Science Ventures. "You need a dedicated clientele to buy into those stocks who understand them, and don't just expect to make a quick buck. Swiss investors seem to understand, seem to appreciate, and seem to make money." 